\title{
Multifocal tuberculosis
}

Sir,

A 35-year-old HIV-infected patient was attended at our district hospital's antiretroviral (ART) center with a history of fever, cough, and shortness of breath. He also complained of back pain. The clinical examination revealed tenderness over the D11/12 spine, although the spine was stable and had no neurological deficit. He had 6 months of nonadherence to antiretroviral (ARV) drugs. Two years back, he was found HIV seropositive with CD4 ${ }^{+}$T-cell count 361/ $\mu \mathrm{l}$ and screening for Mycobacterium tuberculosis in the sputum, including nucleic acid amplification test, had been negative. He was started on ARV drugs tenofovir, lamivudine, and efavirenz. However, due to migration, he had not attended the ART center for the past 6 months. At the ART center, he was categorized as "lost to follow-up." The CD4 ${ }^{+}$T-cell count decreased to $261 / \mu \mathrm{l}$ this time, and the ESR was $126 \mathrm{~mm} / \mathrm{hr}$. In the sputum, a nucleic acid amplification test revealed rifampicin-sensitive $M$. TB. A chest X-ray (Figure 1a) showed localized hydropneumothorax in the right lung and infiltrations in the left lung. Radiographs of the spine (Figure 1b and c) showed wedging of the D11 vertebral body with complete loss of intervertebral disc space between D11/12 and a fusiform abscess around these vertebrae. The sagittal index was $18^{\circ}$. All these radiographic findings indicated type II of Gulhane Askeri Tip Akademisi classification. ${ }^{1}$ At D11 and D12, CT scan axial scans (Figure 1d and e) showed $16 \mathrm{~mm}$ thick, soft tissue (abscess) around the vertebral bodies. The patient was started with four antituberculous drugs along with antiretroviral drugs. In a few months, the patient's chest lesions subsided and the severity of his back pain reduced. The patient was referred to the spinal clinic for drainage of a paravertebral abscess.

In high burden tuberculosis countries, TB is prevalent among HIV seropositive individuals. For example, the prevalence of tuberculosis is $13.3 \%$ in ARV-naïve HIV seropositive cases in high-burden tuberculosis region. ${ }^{2}$ Active tuberculosis is 18 times more common in HIV-positive individuals than in HIV-negative people. Extrapulmonary TB is more likely to manifest in HIV-positive cases. ${ }^{3}$

Poor adherence to ARV drugs and low CD4 counts are the determinant factors in $\mathrm{HIV} / \mathrm{TB}$ coinfection. A recent study
Access this article online

Website:

http://nepjol.info/index.php/AJMS

DOI: 10.3126/ajms.v13i1.41430

E-ISSN: 2091-0576

P-ISSN: 2467-9100

Copyright (c) 2022 Asian Journal of Medical Sciences

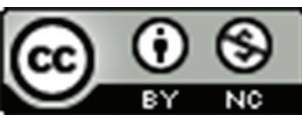

This work is licensed under a Creative Commons Attribution-NonCommercial 4.0 International License.

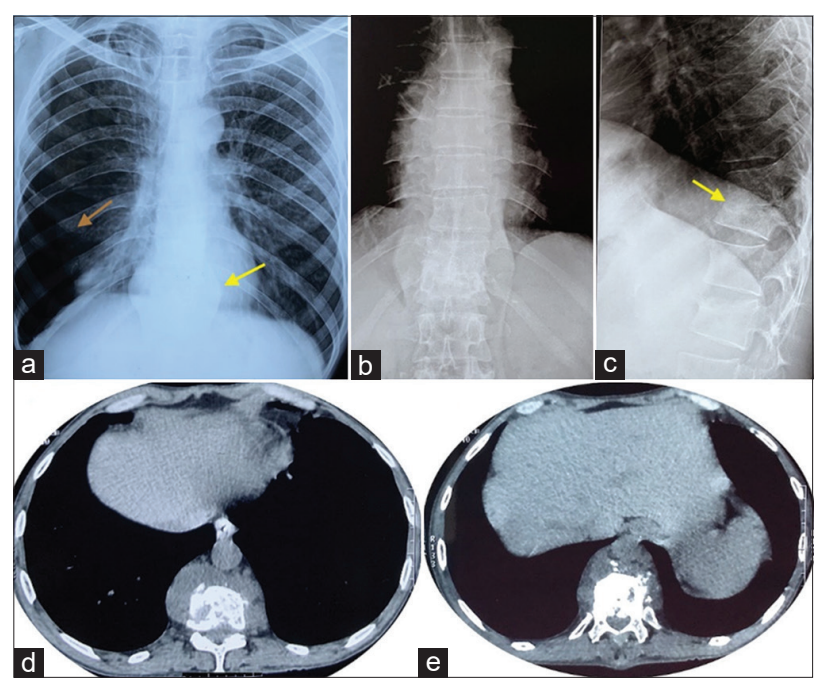

Figure 1: Figure $1 \mathrm{a}-\mathrm{A}$ chest $\mathrm{X}$-ray showing localized hydropneumothorax in the right lung and infiltrations in the left lung. Figure $1 \mathrm{~b}$ and $1 \mathrm{c}-$ Radiographs of the spine showing wedging of the D11 vertebral body with complete loss of intervertebral disc space between D11/12 and a fusiform abscess around these vertebrae. Figure $1 \mathrm{~d}$ and $1 \mathrm{e}-$ At D11 and D12, axial CT scans showing $16 \mathrm{~mm}$ thick, soft tissue (abscess) around the vertebral bodies.

has shown that PLHIV with poor ARV drug adherence after antiretroviral therapy is more likely to develop tuberculosis than with strong ARV drug adherence. ${ }^{4}$ 


\section{Ranjan Kumar Singh}

Consultant Physician, Antiretroviral Therapy Centre, District Hospital Khagaria, Bihar, India

Address for Correspondence: Dr. Ranjan Kumar Singh, Consultant Physician, Antiretroviral Therapy Centre, District Hospital Khagaria, Bihar, India.

Mobile: +91-7903488900. E-mail: dr_ranjankumarsingh@yahoo.com

\section{REFERENCES}

1. Ekinci S, Tatar O, Akpancar S, Bilgic S and Ersen O. Spinal tuberculosis. J Exp Neurosci. 2015;9:89-90.
https://doi.org/10.4137/JEN.S32842

2. Singh RK. Neglected tropical diseases vs tuberculosis in HIV-a cohort study. J Assoc Physicians India 2018;66(5):102.

3. Tuberculosis. World Health Organization. Available from: https:// www.who.int/news-room/fact-sheets/detail/tuberculosis\# [Last accessed on 2021 Oct 15].

4. Abdu M, Ali Y, Anteneh S, Yesuf M, Birhanu A, Mohamed S, et al. Determinant factors for the occurrence of tuberculosis after initiation of antiretroviral treatment among adult patients living with HIV at dessie referral hospital, South Wollo, Northeast Ethiopia, 2020. PLoS One. 2021;16(3):e0248490.

https://doi.org/10.1371/journal.pone.0248490

\section{Authors Contribution:}

The author confirms sole responsibility for the following: study conception and design, data collection, manuscript, and image preparation.

Work attributed to:

Antiretroviral Therapy Centre, District Hospital Khagaria, Bihar, India

Orcid ID:

Dr. Ranjan Kumar Singh - (1) https://orcid.org/0000-0002-0806-8291

Source of Support: Nil, Conflict of Interest: None declared. 